\title{
A Polarimetric Ultra-Wide Band Field Scatterometer
}

\author{
R. De Porrata-Dòria, A. Broquetas, X. Fàbregas \\ A.M.R. Group. Department of Signal Theory and Communications \\ Universitat Politècnica de Catalunya \\ C/Sor Eulalia d'Anzizu, s/n, 08034. Building D3. Barcelona. Catalonia (Spain) \\ Tel.: (343) 401-73-61, Fax: (343) 401-72-32, E-Mail: ramir@voltor.upc.es.
}

\begin{abstract}
TERESA" (TErrestrial Radar Equipment for Scattering Analysis) is a ground-based, fully polarimetric scatterometer operative in the $\mathrm{S}, \mathrm{C}, \mathrm{X}$, and $\mathrm{Ku}$ bands. It has been designed to obtain the complete backscattering matrix of terrain and oceanographic surfaces with an extensive information of its variation with frequency and incident angle. The system is able to mesure the doppler spectrum of the illuminated scene as well. This paper briefly describes the specifications and structure of the system and the first results obtained.
\end{abstract}

\section{1.- INTRODUCTION}

Scatterometers have proved to be extremely valuable tools in order to establish a link between the geophysical parameters of a natural surface and its scattering behaviour at microwave frequencies. They are used in measurement campaigns to characterize the full backscattering matrix of terrain and oceanographic surfaces as a function of frequency, elevation angle, and parameters of the surfaces. These parameters can be moisture, surface roughnes, level of vegetation, sea-surface wind field, etc. However, most of the existing scatterometers are restricted to narrow-band or multiband single-frequency configurations.

\section{2.- TERESA}

In this context, the Antennas, Microwave and Radar group of the Universitat Politècnica de Catalunya (U.P.C.) has carried out the design, development and characterization of an ultra-wide band polarimetric scatterometer called "TERESA" (TErrestrial Radar Equipment for Scattering Analysis). The main requirements of the system were:

1) Obtention of scattering measurements with high accuracy and high dynamic range, covering the possible scattering values of the majority of natural surfaces [1].

2) Capability of measuring the complete backscattering matrix, that is, the $\mathrm{HH}, \mathrm{HV}, \mathrm{VH}$ and $\mathrm{VV}$ polarimetric combinations.

3) Frequency range large enough to cover the operative frequencies of the main existing SAR.

4) Range of incident angles comprising those used by existing SAR.

5) Internal and external calibration to avoid, respectively, long-term and short-term systematic errors.

6) Robust and easy to manipulate mast, capable of lifting the antennas to a height between 12 and 14 metres.

7) Use of a computer to carry out simultaneously the following tasks: Control of the RF equipment, electronic control of the elevation and azimuth angles, automatization of the measurements and calibrations, and a first analysis of the data obtained.

8) High versatility, mobility, resistance against corrosion and adverse climatic conditions and high insensitivity to temperature changes.

Moreover, the consumption of the whole system has been minimized in order to lenghten its autonomy, and a complete transport structure has been constructed to increase its mobility. In broad outline, the specifications of TERESA are summarized in tables 1 and 2 .

\begin{tabular}{|c|c|c|}
\hline Parameter & Value & Observations \\
\hline Polarization & $\mathrm{HH}, \mathrm{HV}, \mathrm{VH}, \mathrm{VV}$ & $\begin{array}{c}\text { Maximum polarimetric } \\
\text { information }\end{array}$ \\
\hline $\begin{array}{c}\text { Frequency } \\
\text { range }\end{array}$ & $\begin{array}{c}2-18 \mathrm{GHz} \\
(\mathrm{S}, \mathrm{C}, \mathrm{X}, \mathrm{Ku} \\
\text { bands })\end{array}$ & $\begin{array}{c}\text { Comprises the majority of } \\
\text { existing SAR }\end{array}$ \\
\hline $\begin{array}{c}\text { Range in } \\
\text { elevation }\end{array}$ & $0-60^{\circ}$ off-nadir & $\begin{array}{c}\text { Extensive angular } \\
\text { information }\end{array}$ \\
\hline $\begin{array}{c}\text { Range in } \\
\text { azimuth }\end{array}$ & $0-360^{\circ}$ & $\begin{array}{c}\text { To maximize the number } \\
\text { of independent samples }\end{array}$ \\
\hline $\begin{array}{c}\text { Minimum } \\
\text { transmitted } \\
\text { power }\end{array}$ & $20 \mathrm{dBm}$ & To maximize sensibility \\
\hline
\end{tabular}

Table 1.- Specifications of TERESA

\begin{tabular}{|c|c|}
\hline Parameter & Value \\
\hline Dynamic range & $80 \mathrm{~dB}$ \\
\hline Minimum $\sigma_{0}$ measurable & $-55 \mathrm{~dB}$ \\
\hline Maximum $\sigma_{0}$ measurable & $25 \mathrm{~dB}$ \\
\hline Minimum signal/noise ratio & $10 \mathrm{~dB}$ \\
\hline
\end{tabular}

Table 2.- Specifications at $5,3 \mathrm{GHz}$ (ERS-1 operative freq.) 
The scatterometer consists of an interval unit on the ground and an external unit on top of a 14 metres high telescopic mast (fig. 1). The internal unit consists of a portable computer, a network analyzer HP-8720C and the circuits of control and power supply. The external unit is formed by the antennas and its mechanical complements, the elevation actuator, the azimuth rotator and the RF devices. Both units are interconnected by means of six cables: two multi-wire for control aplications and four for RF signals.

- Processing unit: The computer performs all the tasks of instrumentation control, electronic circuit control, external and internal calibration, data acquisition and data pre-processing. All the previous tasks are performed by a single program that uses a graphical user interface. Two main measurement configurations are provided: manual and automatic. The second one allows multiple combinations of antenna orientations and measurements arranged in a nested-loop structure.

- Microwave circuits: A compact and low cost HP-8720C network analyzer, capable of measuring up to $20 \mathrm{GHz}$, is used as the transmission/reception main module [2]. It normally operates in sweep-frequency mode but it provides as well single-frequency mode, which is used to measure doppler spectrums. The analyzer has four ports: One for transmission and three for reception ( $A, B$ y R). Being its maximum output power $10 \mathrm{dBm}$, the transmitted signal is amplified in the external unit by an amplifier operative from 2 to $18 \mathrm{GHz}$, capable of obtaining $20 \mathrm{dBm}$ of output power all over its frequency range. The amplified signal is delivered to the transmitting antenna through an electromechanical switch, which selects between horizontal and vertical polarizations. Two other electromechanical switches connected to the receiving antenna switch between the configuration of internal calibration and the configuration of measurement/external calibration.

By means of a directional coupler, a sample of the transmitted signal is obtained and delivered to the reference port $(R)$ of the analyzer. This way, several goals are simultaneously satisfied: First, phase lock is obtained and the reference signal is acquired. Secondly, the effect of performance variations in the RF devices is greatly reduced, resulting in a high insensitivity to temperature changes. Third, the effective measurement ports are automatically moved to the external unit, decreasing this way the requirements over the parameters of the time-domain transformation. Finally, the delay between the transmission/reception path and the reference path is greatly reduced, which minimizes the phase noise effects and prevents the received signal from falling outside the intermediate frequency filter of the receiver.

- Antennas: TERESA operates with two separated antennas, one for transmission and one for reception. In order to obtain enough directivity, two offset reflectors of $60 \mathrm{~cm}$ diameter have been chosen. One of the big goals of the system was to measure in a broad bandwidth without having to change the horns for each frequency band. For that purpose, the scatterometer uses two double polarization quad-ridge horns operative between 2 and $18 \mathrm{GHz}$.

- Control circuits: The control of the three electromechanical switches, as well as the control of the azimuth rotator and elevation actuator are carried out by the electronic control module located at the internal unit. Moreover, it supplies and monitors the power required by the microwave amplifier, and supervises the temperature level in the external unit.

- Support structure: The system is transported by a 5,5 metres long trailer, which can be adapted to many vehicles. The trailer and a $2200 \mathrm{~W}$ generating set provide the system with great mobility and autonomy, and facilitate the measurement process in a natural environment. A telescopic mast lifts the antennas to the desired height, with a maximum height of 14 metres and a maximum headload of $100 \mathrm{Kg}$. The mast can be tilted up to $45^{\circ}$, something completely necessary for measuring at perpendicular incidence.

- Calibration: The system uses two types of calibration: internal and external [3]. The first corrects the short-term variations that affect the RF and electronic devices of the system, and consists of a comparison between the power levels of the transmitted signal and a reference signal. It is, therefore, a non-polarimetric calibration. External calibration is, on the contrary, a polarimetric calibration, and its objective is the minimization of the systematic errors present in the sy stem. The system can use three different external calibration methods: GCT (General Calibration Technique) [4], Wiesbeck [5], and TSC (Target Spinor Calibration) [6]. The calibrators normally used are a trihedral and a dihedral (at $0^{\circ}$ and $45^{\circ}$ ). At low frequencies $(2-5 \mathrm{GHz})$ active calibrators will be used.

\section{FIRST RESULTS}

The first measurements obtained with the scatterometer have been carried out in an anechoic chamber in order to verifiy the system operation. From these results, the system has been completely characterized, the software has been improved and the RF devices, as well as the electronic circuits, have been adjusted and optimized.

TERESA has already been successfully applied to a few natural surfaces. The polarimetric scattering behaviour of a stony surface has been completely characterized, and several interesting results have been achieved. This measurement was carried out on the roof of the laboratory building, and the target was a layer around $10 \mathrm{~cm}$ high of dry, small stones. The backscattering coefficients of this surface were measured from 12 to $16 \mathrm{GHz}$ with 401 points, and 140 independent samples for each frequency point were taken. Because of the surface geometry, a high level of multiple scattering and, therefore, cross-polar components, was expected. This was later corroborated with the averaged results obtained (fig. 2). 
The probability density functions calculated agree to a great extent with the expected rayleigh functions. Other interesting conclusions have been reached, but maybe is worth mentioning that Bragg resonances have been clearly detected and are currently under study.

Several measurement campaigns have been planned for 1995 , among which the characterization of sea reflectivity in a $100 \mathrm{~m}$ long water flume located at the U.P.C. is of special interest.

\section{CONCLUSIONS}

A new scatterometer has been presented under the name of "TERESA" (TErrestrial Radar Equipment for Scattering Analysis). It is a ground-based, fully polarimetric scatterometer operative in the S,C,X and $\mathrm{Ku}$ bands, that has been developed at the Antennas, Microwave and Radar group of the U.P.C. The system has a great dynamic range and a high degree of flexibility and reliability. To obtain maximum accuracy, internal and external calibration are used. The antennas are located at the top of a trailer-mounted telescopic mast, giving a maximum height of 14 metres above ground. TERESA is also capable of measuring doppler spectrum.

The scatterometer is intended to carry out measurement campaigns continuously, so any proposals from other research groups will be welcome.

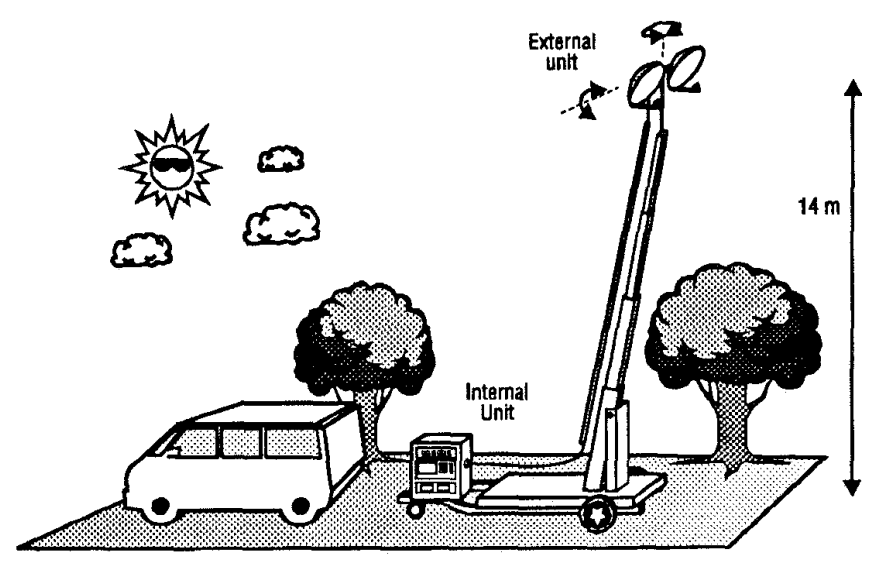

Figure 1.- Structure of TERESA

\section{ACKNOWLEDGMENTS}

This work has been supported by the Spanish Comission of Science and Technology (CICYT, TIC 92-0645).

\section{REFERENCES}

[1] F.T. Ulaby, M.C. Dobson, "Radar Scattering Statistics for Terrain", Artech House, 1989.

[2] F.T. Ulaby et al., "A Millimeterwave Network Analyzer Based Scatterometer", IEEE Transactions on Geoscience and Remote Sensing, Vol. 26, No. 1, January 1988, pp. 75-81.

[3] F.T Ulaby et al., "Microwave Remote Sensing", AddisonWesley Publishing Company, Vol. II, 1982.

[4] M.W. Whitt et al, "A General Polarimetric Radar Calibration Technique", IEEE Transactions on Geoscience and Remote Sensing, Vol. 39, No. 1, January 1991.

[5] W. Wiesbeck, S. Riegger, "A Complete Error Model for Free Space Polarimetric Measurements", IEEE Trans. AP, vol. AP-39, August 1991, pp. 1105-1111.

[6] X. Fàbregas, A. Broquetas, J. Romeu, L. Jofre, "Polarimetric Calibration using Pauli Matrices Decomposition" , Progress in Electromagnetics Research Symposium (PIERS), Noodwijk, The Netherlands, July 1994, pp. 376.

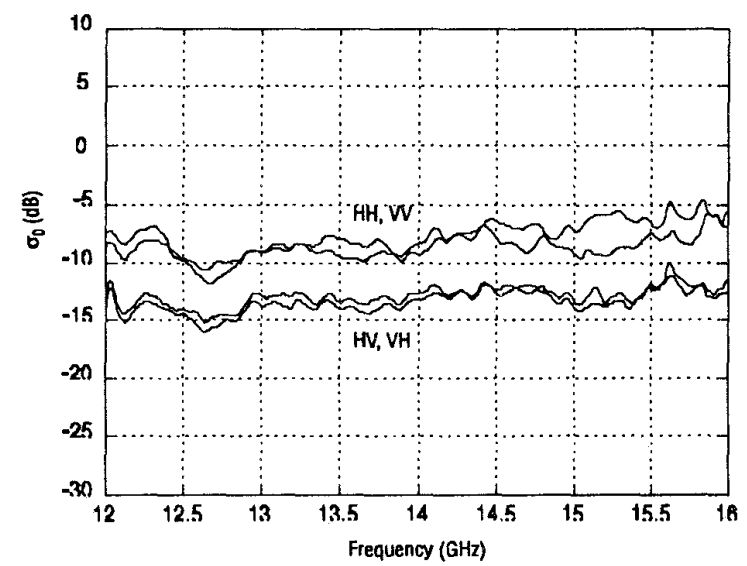

Fig. 2.- Backscattering coefficients of a stony terrain 